\title{
Characterization of Endolithic Culturable Microbial Communities in Carbonate Rocks from a Typical Karst Canyon in Guizhou (China)
}

\author{
YUAN TANG ${ }^{1}$, JIAN-ZHONG CHENG ${ }^{1}$ and BIN LIAN²* \\ ${ }^{1}$ State Key Laboratory of Environmental Geochemistry, Institute of Geochemistry, \\ Chinese Academy of Sciences, Guiyang, PR China \\ ${ }_{2}^{2}$ Jiangsu Key Laboratory for Microbes and Functional Genomics, Jiangsu Engineering and Technology Research Center \\ for Microbiology, College of Life Science, Nanjing Normal University, Nanjing, PR China
}

Submitted 9 December 2015, revised 24 February 2016, accepted 26 August 2016

\begin{abstract}
The endolithic environment is a ubiquitous habitat for microorganisms and a critical interface between biology and geology. In this study, a culture-based method and the phylogenetic analysis based on $16 \mathrm{~S}$ rRNA and internal transcribed spacer (ITS) sequences were used to investigate the diversity of endolithic bacteria and fungi in two main types of carbonate rocks (namely dolomite and limestone) from Nanjiang Canyon in Guizhou karst area, China. The results of bacterial diversity indicated that all bacteria isolated from dolomite and limestone rocks were divided into 4 bacterial groups, including Proteobacteria, Actinobacteria, Firmicutes and Bacteroidetes. For these two kinds of rocks, Proteobacteria was the first dominant group, and Gammaproteobacteria occupied the greatest proportion which might be closely related to Pseudomonas in phylogeny to be the most dominant genera after isolation. Actinobacteria and Bacillus bacteria were also widespread in these two kinds of rock environments. There were only 9 and 8 strains of fungi isolated from dolomite and limestone respectively, which all belonged to Ascomycota. To the best of our knowledge, this is the first report on diversity of endolithic culturable bacteria and fungi in carbonate rocks in Guizhou karst region. These microorganisms may play an important and unprecedented role in the carbonate rock weathering during the long history of geological evolution.
\end{abstract}

Ke y words: endolithic bacteria, endolithic fungi, carbonate rock

\section{Introduction}

The endolithic environment, the tiny pore and crack space in rocks, is a ubiquitous habitat for microorganisms and a critical interface between biology and geology (Friedmann, 1982; Walker and Pace, 2007a). Microorganisms native to the endolithic environment must possess adaptive ability and tolerance to severe stresses including rapid temperature variations, oligotrophy, desiccation, and high UV flux (Sigler et al., 2003; Selbmann et al., 2013). Communities of microorganisms that inhabit endolithic environments include autotrophic and heterotrophic bacteria, fungi, algae, and lichens (Sigler et al., 2003). The endolithic microorganisms rarely existed by means of single colony formed by a single species, while they usually grew collectively to form microbial community with complex, various structures and functions (Gorbushina et al., 2004; Gorbushina, 2007). Nowadays, endolithic microorganisms have been observed not only in a variety of extreme terrestrial ecosystems but also in temperate environments
(Gerrath et al., 2000; Wierzchos et al., 2006; Horath and Bachofen, 2009; Wong et al., 2010; Tang et al., 2012). They also have been detected inhabiting a variety of rock types such as halite, sandstone, quartz, gypsum, dolomite and limestone (Dong et al., 2007; Gorbushina, 2007; Tang et al., 2012; Roldan et al., 2014).

Nowadays, many investigations of endolithic microbial communities used culture-independent techniques (Sigler et al., 2003; Walker and Pace, 2007b; Horath and Bachofen, 2009; Wong et al., 2010). Although, cultureindependent methods can provide important information about the diversity of phylogenetic groups in endolithic environments, pure cultures are still indispensable for the determination of the metabolic activity of microorganisms, which can be significantly different even among closely related phylotypes (Spring et al., 2015). In addition, the culturable microorganisms account for about $0.001 \sim 15 \%$ of the total microorganisms of environmental samples (Tamaki et al., 2005). Thus, a considerable part identified by culture-independent method is uncultured microbial species. Pure

\footnotetext{
* Corresponding author: B. Lian, Jiangsu Key Laboratory for Microbes and Functional Genomics, Jiangsu Engineering and Technology Research Center for Microbiology, College of Life Science, Nanjing Normal University, Nanjing, PR China; e-mail: bin2368@vip.163.com
} 
culture method played and plays an irreplaceable role in exploring microbial community structures, especially in the following aspects, such as new species or special functional microbes, etc (De Leo et al., 2012; Krakova et al., 2015). However, to date, no study has examined the endolithic microbial community in Guizhou karst environment using culture-dependent method. This method has the potential to improve our understanding of microbial diversity and facilitate functional studies of endolithic microorganisms.

Guizhou, a province in southwest of China, is one of the three largest developing karst areas in the world. The carbonate rock area is $130,000 \mathrm{~km}^{2}$, covering $73.8 \%$ of total land surface area of the province. The weathering of carbonate rocks influences the geochemical compositions of rocks, soils, the atmosphere, and organisms, and the transfer process of matter and energy in the karst environment (Lian et al., 2010). Endolithic microorganisms have been found to be directly and indirectly involved in the weathering of carbonate rocks. Papida et al. (2000) found that a mixed microbial population exacerbated physical weathering of carbonate rocks. The endolithic microorganisms play an important and unprecedented role in the carbonate rock weathering during the long history of geological evolution. So, the aim of the present study was therefore to investigate the endolithic microbial diversity in dolomite and limestone rocks in karst area of Guizhou Province using culture-dependent techniques. Combined with the culture-independent method at the early stage (Tang and Lian, 2012; Tang et al., 2012), endolithic microbial diversity of carbonate rocks could be reflected more fully. Meanwhile, the research laid the foundation to further explore the carbonate rock weathering by using the microbial resources in the karst endolithic environment.

\section{Experimental}

\section{Materials and Methods}

Site description and sample collection. Nanjiang canyon $\left(26^{\circ} 56^{\prime \prime} \mathrm{N}, 106^{\circ} 58^{\prime \prime} \mathrm{E}\right)$ is a typical karst canyon, which is praised as "Karst Ecosystem Museum". It is located in Kaiyang County of Guizhou Province, southwest China. Details of the site are given in our previous study (Tang and Lian, 2012; Tang et al., 2012). There are a lot of exposed carbonate rocks in this area. The dolomite and limestone rocks are weathered and porous. The soil developed on its weathering crust is non-zonal soil with shallow soil layers and no apparent genetic layers. In this area, three Triassic dolomite (D1-D3) and three Triassic limestone samples (L1-L3) up to a depth of $\sim 1 \mathrm{~cm}$ were collected using a sterile rock chisel and placed in sterile bags on ice. The samples were kept at $4^{\circ} \mathrm{C}$ until subjected to microbial isolation. All samples were collected in September 2009.

Powder X-ray diffraction. For mineralogy in the dolomite and limestone rock samples, powder X-ray diffraction patterns were obtained using CuKa radiation at $40 \mathrm{kV}$ with an X-ray diffractometer (D/Max-2200/ $\mathrm{PC}$, Rigaku). The results revealed 2 dolomite samples to be pure dolomite rocks and one dolomite sample to be mostly dolomite (99\%) with trace amounts of anorthose. The 3 limestone samples were mostly calcite (97-99\%) containing trace of dolomite and quartz.

Isolation and enumeration of microorganisms. In accordance with the requirements of aseptic technique, the mineral powder of each crush rock sample was scraped. After serial dilution, they were coated on beef extract-peptone agar medium ( $5 \mathrm{~g} / \mathrm{l}$ beef extract, $10 \mathrm{~g} / \mathrm{l}$ peptone and $15 \mathrm{~g} / \mathrm{l}$ agar) and Martin culture medium $\left(1 \mathrm{~g} / \mathrm{l} \mathrm{K}_{2} \mathrm{HPO}_{4}, 0.5 \mathrm{~g} / 1 \mathrm{MgSO}_{4} \cdot 7 \mathrm{H}_{2} \mathrm{O}, 5 \mathrm{~g} / \mathrm{l}\right.$ peptone, $10 \mathrm{~g} / \mathrm{l}$ glucose, $15 \sim 20 \mathrm{~g} / \mathrm{l}$ agar and $3.3 \mathrm{ml} / 1 \mathrm{1} \%$ streptomycin aqueous solution). Then they were reversely cultivated under constant temperature of $30^{\circ} \mathrm{C}$. After $2 \sim 3$ days for bacteria or $5 \sim 7$ days for fungi, the colony counting could be obtained. The single colonies with different phenotypes, were picked up and the purified strains were transferred to the corresponding agar slants for conservation at $4^{\circ} \mathrm{C}$.

DNA extraction, PCR amplification, and sequencing. DNA extraction and PCR amplification were performed using the TIANcombi DNA Lyse\&Amp PCR Kit (Tiangen Biochemical technology Co., Ltd., China). The bacterial universal primers 27F (5'-AGAGTTTGATCCTGGCTCAG-3') and 1492R (5'-GGTTACCTTGTTACGACTT-3') and fungal universal primers ITS1 (5'-TCCGTAGGTGAACCTGCGG-3') and ITS4 (5'-TCCTCCGCTTATTGATATGC-3'), were used to amplify the bacterial 16S rDNA and fungal internal transcribed spacer (ITS) sequences, respectively. All of the primers were synthesized by Shanghai Sangong Co., Ltd., China.

All reactions were carried out in a $50 \mu$ reaction mixture, containing $25 \mu \mathrm{l}$ of $2 \times$ PCR Reagent, $1.25 \mu \mathrm{l}$ of forward primer and reverse primer $(10 \mu \mathrm{M})$ respectively and $5 \mu \mathrm{l}$ of DNA template. PCR was run under the following conditions: initial denaturation at $94^{\circ} \mathrm{C}$ for $5 \mathrm{~min}$; followed by 30 circles of $1 \mathrm{~min}$ denaturation at $94^{\circ} \mathrm{C}, 1 \mathrm{~min}$ annealing at $52^{\circ} \mathrm{C}, 2 \mathrm{~min}$ extension at $72^{\circ} \mathrm{C}$, and a final extension step of $10 \mathrm{~min}$ at $72^{\circ} \mathrm{C}$. The results of PCR amplification were confirmed using $1 \%$ agarose gel, stained with SYBR Safe $10.000 \times$ in DMSO (Invitrogen). PCR products were subsequently purified using PCR purification kit (E.A.N.A. Gel Extraction kit, OMEGA, USA) and subjected to sequencing in an ABI PRISM 3730 automatic sequencer (Shanghai Sangon Co., Ltd., China). 
Phylogenetic analysis. DNA sequences were analyzed using Bellerophon (Huber et al., 2004) and CHIMERA_CHECK (Cole et al., 2003) software to remove chimeric artifacts. The sequences were considered to be of the same phylotype if they were $\geq 97 \%$ similar to one another over the region of the 16s or ITS rRNA gene sequenced (Stackebrandt and Ebers, 2006). Then the effective sequences were compared with known sequences in the NCBI database (http://www.ncbi.nih. gov/) by Basic Local Alignment Search Tool (BLAST) (Altschul et al., 1990). The sequences were aligned using Clustal X software (Thompson et al., 1997), and phylogenetic trees were constructed with the Mega 4.0 program package using the neighbor-joining method (Kumar et al., 2004). Bootstrap confidence values were obtained with 1000 replicates. The trees were constructed by calculating the Kimura distance (Kimura, 1980).

Nucleotide sequence Accession numbers. The nucleotide sequences reported in this study have been deposited in GenBank under accession numbers JN650544-JN650602.

\section{Results}

Isolation and enumeration of microorganisms. Beef extract-peptone agar medium was utilized to isolate bacteria of rock samples. There were 39 strains and 26 strains of bacteria with different phenotypic characteristics in dolomite and limestone respectively. Fungi of rock samples were separated by Martin culture medium, and dolomite and limestone respectively obtained 9 and 8 strains of fungi with different colony phenotypes. It was calculated that the culturable bacteria of dolomite and limestone were about $2.3 \times 10^{5} \mathrm{CFU} / \mathrm{g}$ and $2.0 \times 10^{5} \mathrm{CFU} / \mathrm{g}$ by using dilutionplate method; while the culturable fungi were about $7.7 \times 10^{3} \mathrm{CFU} / g$ and $3.0 \times 10^{3} \mathrm{CFU} / \mathrm{g}$ respectively.

Diversity of the bacterial 16S rRNA gene sequences from dolomite rocks. There were 39 effective sequences in total by sequencing $16 \mathrm{~S}$ rDNA for the isolates of 39 strains of dolomite. The alignment results of similarity indicated that they were classified into 4 phyla, 15 genera and 26 species (Table I). These 39 strains of bacteria showed high similarity with the known $16 \mathrm{~S}$ rDNA sequences in database, namely $98 \sim 100 \%$.

The sequence analysis of $16 \mathrm{~S}$ rDNA (see Table I and Fig. 1) illustrates that 39 strains of bacteria from dolomite were classified into 4 major bacteria groups. More than $53.8 \%$ of them belonged to Proteobacteria, which including 12 strains of Gammaproteobacteria, accounting for 30.8\%; 5 strains of Alphaproteobacteria, accounting for $12.8 \%$; and 4 strains of Betaproteobacteria, accounting for $10.2 \%$. In addition, 10 strains were from Actinobacteria, and accounted for $25.7 \%$, while 7 strains were Firmicutes, accounting for 17.9\%. Moreover, one strain belonged to Bacteroidetes, accounting for $2.6 \%$.

Gammaproteobacteria, as one subphylum of Proteobacteria, accounted for the highest ratio of culturable bacteria in the endolithic dolomite environment so that it was regarded as the most dominant group obtained by isolation. The 10 strains of bacteria in the group, accounting for $25.6 \%$, had close relations with Pseudomonas in phylogeny, and the similarity of 16S rDNA sequences was $99 \%$. Thus, the group was the most dominant bacterial genus acquired by isolation. Therein, four strains were closely associated with Pseudomonas putida, 1 strain was highly homologous to Pseudomonas nitroreducens. In Alphaproteobacteria, there were 2 strains which were closely related to Brevundimonas and Sphingobium respectively and 1 strain had homology of $99 \%$ with Sphingobium. Besides, 4 strains of bacteria belonged to Betaproteobacteria, where 2 strains were Duganella and the other 2 strains belonged to Marseille.

Actinobacteria was the second dominant group of the culturable bacteria from dolomite. In this group, 4 strains of bacteria had a close genetic relationship with Arthrobacter; three of them were highly homologous with Rhodococcus; the homology of two strains and Streptomyces zaomyceticus (FJ792553) reached $100 \%$; and the rest one was $99 \%$ homologous with Microbacterium oxydans (HQ202812).

There were 7 strains of bacteria in Firmicutes, including 6 Bacillus, which were the second dominant genera of the culturable bacteria from dolomite. In this group, three of them were $99 \%$ homologous with Bacillus cereus (GU969128), two showed high homology with Bacillus sphaericus (DQ286315), and one was $100 \%$ homologous with Bacillus simplex (JF496520). Moreover, DCB46 was 99\% homologous with Paenibacillus sp. (FJ006903).

Only one strain of bacteria belonged to Bacteroidetes, which was $99 \%$ homologous with Dyadobacter sp. (HQ231938).

Diversity of the bacterial 16S rRNA gene sequences from limestone rocks. $16 \mathrm{~S}$ rDNA of 26 bacterium isolates from limestone was sequenced to obtain 26 effective sequences in total. The relationships between $16 \mathrm{~S}$ rDNA sequence of the bacteria isolated from limestone and the most similar sequence in GenBank database are listed in Table II. It can be seen that they were divided into 4 phyla, 13 genera and 17 species. There was a high similarity between the 26 strains of bacteria and the known 16S rDNA sequences in GenBank database. Among them, the similarity of LCB37 was $96 \%$ only, while that of the rest was higher than $97 \%$.

As indicated by $16 \mathrm{~S}$ rDNA phylogenetic analysis, the 26 strains of bacteria isolated from limestone were assigned to 4 major phylogenetic groups (Fig. 2). It can 
Table I

Similarity analysis of $16 \mathrm{~S}$ rDNA sequences of isolates from dolomite rocks

\begin{tabular}{|c|c|c|c|}
\hline $\begin{array}{l}\text { Representative isolate } \\
\text { (accession no.) }\end{array}$ & $\begin{array}{l}\text { No. of isolates } \\
\text { in OUT* }\end{array}$ & Nearest type strain (accession no.) & $\begin{array}{l}\text { Similarity } \\
(\%)\end{array}$ \\
\hline Actinobacteria & 10 & & \\
\hline Arthrobacter & 4 & & \\
\hline DCB14(JN650552) & 2 & Arthrobacter sp. (HM165265) & 99 \\
\hline DCB16(JN650554) & 1 & Arthrobacter sp. (HQ166103) & 99 \\
\hline DCB48(JN650561) & 1 & Arthrobacter sp. (FN794213) & 99 \\
\hline Microbacterium & 1 & & \\
\hline DCB18(JN650556) & 1 & Microbacterium oxydans (HQ202812) & 99 \\
\hline Rhodococcus & 3 & & \\
\hline DCB15(JN650553) & 1 & Rhodococcus sp. (JF900087) & 99 \\
\hline DCB17(JN650555) & 2 & Rhodococcus sp. (EF612316) & 99 \\
\hline Streptomyces & 2 & & \\
\hline DCB61(JN650569) & 2 & Streptomyces zaomyceticus (FJ792553) & 100 \\
\hline Bacteroidetes & 1 & & \\
\hline Dyadobacter & 1 & & \\
\hline DCB47(JN650560) & 1 & Dyadobacter sp. (HQ231938) & 99 \\
\hline Firmicutes & 7 & & \\
\hline Paenibacillus & 1 & & \\
\hline DCB46 (JN650559) & 1 & Paenibacillus sp. (FJ006903) & 99 \\
\hline Bacillus & 6 & & \\
\hline DCB1(JN650544) & 3 & Bacillus cereus (GU969128) & 99 \\
\hline DCB23(JN650558) & 1 & Bacillus simplex (JF496520) & 100 \\
\hline DCB8(JN650548) & 2 & Bacillus sphaericus(DQ286315) & 99 \\
\hline Proteobacteria & 21 & & \\
\hline Alphaproteobacteria & 5 & & \\
\hline Brevundimonas & 2 & & \\
\hline DCB19(JN650557) & 1 & Brevundimonas vesicularis (FJ999941) & 99 \\
\hline DCB60(JN650568) & 1 & Brevundimonas sp. (DQ778038) & 99 \\
\hline Methylobacterium & 1 & & \\
\hline DCB49(JN650562) & 1 & Methylobacterium sp. (FN868959) & 99 \\
\hline Sphingobium & 2 & & \\
\hline DCB53(JN650564) & 2 & Sphingobium amiense (JF459961) & 100 \\
\hline Betaproteobacteria & 4 & & \\
\hline Duganella & 2 & & \\
\hline DCB58(JN650566) & 1 & Duganella sp. (JF778719) & 99 \\
\hline DCB59(JN650567) & 1 & Duganella zoogloeoides (NR_025833) & 99 \\
\hline Massilia & 2 & & \\
\hline DCB52(JN650563) & 1 & Massilia sp. (DQ257420) & 99 \\
\hline DCB56(JN650565) & 1 & Massilia sp. (AB552860) & 98 \\
\hline Gammaproteobacteria & 12 & & \\
\hline Enterobacter & 1 & & \\
\hline DCB6(JN650546) & 1 & Enterobacter amnigenus (DQ481471) & 99 \\
\hline Pseudomonas & 10 & & \\
\hline DCB7(JN650547) & 3 & Pseudomonas sp. (FN547413) & 99 \\
\hline DCB11(JN650550) & 2 & Pseudomonas sp. (AM934695) & 99 \\
\hline DCB13(JN650551) & 4 & Pseudomonas putida (EU118779) & 99 \\
\hline DCB74(JN650570) & 1 & Pseudomonas nitroreducens (EU500825) & 99 \\
\hline Serratia & 1 & & \\
\hline DCB5(JN650545) & 1 & Serratia fonticola (HQ407251) & 99 \\
\hline
\end{tabular}

* The strains were clustered into operational taxonomic units (OTUs) at a level of sequence similarity $\geq 97 \%$. 


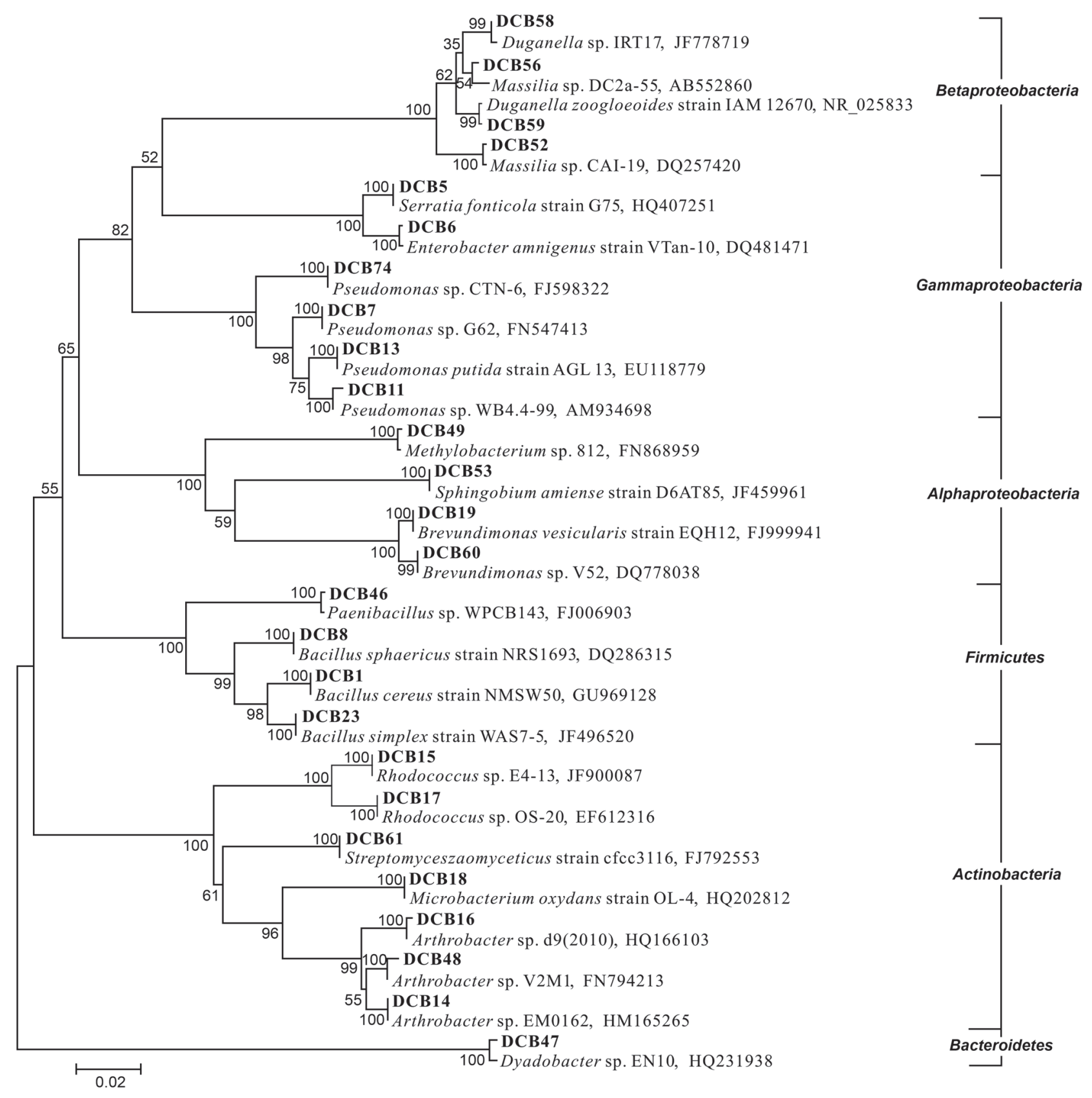

Fig. 1. Phylogenetic relationship based on 16S rRNA gene sequences of culturable bacterial clones isolated from dolomite rocks (in bold type) with closely related sequences from the GenBank database. Neighbor-joining trees; bootstrap values (1,000 replicates) are shown at the nodes

be known that Proteobacteria played a dominant role in bacterial diversity and had 18 strains, taking up $69.3 \%$, including 8 Betaproteobacteria and Gammaproteobacteria, accounting for $30.8 \%$ respectively; 2 strains of Alphaproteobacteria, accounting for $7.7 \%$. In addition, three strains belong to Actinobacteria and three of them were Bacteroidetes, which accounted for $11.5 \%$. Moreover, there were 2 strains of Firmicutes (7.7\%).

As for Proteobacteria, 8 of them belonged to Gammaproteobacteria subphylum, and all of them were Pseudomonas, which was regarded as the first dominant genera of culturable bacteria from limestone. In the subphylum, LCB43 had $100 \%$ similarity to dolo- mite isolate DCB13, which means that they were the same kind of bacteria. In addition, the similarity between them and P. putida (EU118779) reached 99\%. The other 7 strains of bacteria were $100 \%$ similar to Pseudomonas sp. (FJ006865), while as for the species of Pseudomonas, it was needed to be further identified. There were 8 strains of Betaproteobacteria, including 4 Marseille bacteria, which were sub-dominant genera of culturable bacteria from limestone. Moreover, 2 Janthinobacterium, a Duganella, and a Methylibium were included. Only 2 strains in Alphaproteobacteria showed 100\% homology with Brevundimonas intermedia (JF915342). 
Table II

Similarity analysis of $16 \mathrm{~S}$ rDNA sequences of isolates from limestone rocks.

\begin{tabular}{|c|c|c|c|}
\hline $\begin{array}{l}\text { Representative isolate } \\
\quad \text { (accession no.) }\end{array}$ & $\begin{array}{l}\text { No. of isolates } \\
\text { in OUT* }\end{array}$ & Nearest type strain (accession no.) & $\begin{array}{c}\text { Similarity } \\
(\%)\end{array}$ \\
\hline Actinobacteria & 3 & & \\
\hline Arthrobacter & 1 & & \\
\hline LCB65 (JN650582) & 1 & Arthrobacter sp. (HQ231937) & 99 \\
\hline Microbacterium & 1 & & \\
\hline LCB38 (JN650577) & 1 & Microbacterium oxydans (HQ316116) & 99 \\
\hline Oerskovia & 1 & & \\
\hline LCB39 (JN650578) & 1 & Oerskovia paurometabola (HM244951) & 100 \\
\hline Bacteroidetes & 3 & & \\
\hline Flavobacterium & 2 & & \\
\hline LCB34 (JN650574) & 1 & Flavobacterium sp. (HQ425305) & 98 \\
\hline LCB37 (JN650576) & 1 & Flavobacterium sp. (DQ178976) & 96 \\
\hline Sphingobacterium & 1 & & \\
\hline LCB40 (JN650579) & 1 & Sphingobacterium sp. (AM411998) & 99 \\
\hline Firmicutes & 2 & & \\
\hline Bacillus & 1 & & \\
\hline LCB77 (JN650587) & 1 & Bacillus cereus (GU969128) & 99 \\
\hline Staphylococcus & 1 & & \\
\hline LCB44 (JN650581) & 1 & Staphylococcus sp. (EU855210) & 99 \\
\hline Proteobacteria & 18 & & \\
\hline Alphaproteobacteria & 2 & & \\
\hline Brevundimonas & 2 & & \\
\hline LCB32 (JN650573) & 2 & Brevundimonas intermedia (JF915342) & 100 \\
\hline Betaproteobacteria & 8 & & \\
\hline Methylibium & 1 & & \\
\hline LCB69 (JN650585) & 1 & Methylibium sp. (FJ615290) & 99 \\
\hline Duganella & 1 & & \\
\hline LCB66 (JN650583) & 1 & Duganella zoogloeoides (NR_025833) & 99 \\
\hline Janthinobacterium & 2 & & \\
\hline LCB30 (JN650572) & 2 & Janthinobacterium sp. (FN293043) & 99 \\
\hline Massilia & 4 & & \\
\hline LCB36 (JN650576) & 2 & Massilia sp. (DQ257420) & 99 \\
\hline LCB71 (JN650586) & 1 & Massilia sp. (AB552860) & 98 \\
\hline LCB67 (JN650584) & 1 & Massilia sp. (FR865960) & 99 \\
\hline Gammaproteobacteria & 8 & & \\
\hline Pseudomonas & 8 & & \\
\hline LCB43 (JN650580) & 1 & Pseudomonas putida (EU118779) & 99 \\
\hline LCB28 (JN650571) & 7 & Pseudomonas sp. (FJ006865) & 100 \\
\hline
\end{tabular}

* The strains were clustered into operational taxonomic units (OTUs) at a level of sequence similarity $\geq 97 \%$

Three strains of bacteria in Bacteroidetes group were closely related to Flavobacterium and Sphingobacterium, while 3 strains of bacteria in Actinobacteria group were Arthrobacter sp., Microbacterium sp. and Oerskovia sp. respectively. Besides, the similarity between LCB77 of Firmicutes group and dolomite isolate DCB1 was up to $100 \%$. They were $99 \%$ similar with $16 \mathrm{~S}$ rDNA sequences of B. cereus (EU979024), namely type strain. In addition, an isolate of Firmicutes had close relations with Staphylococcus.

Diversity of culturable fungi from dolomite and limestone rocks. ITS sequences for 9 strains of fungi isolates from dolomite and 8 strains of fungi isolates from limestone were compared with the sequence 


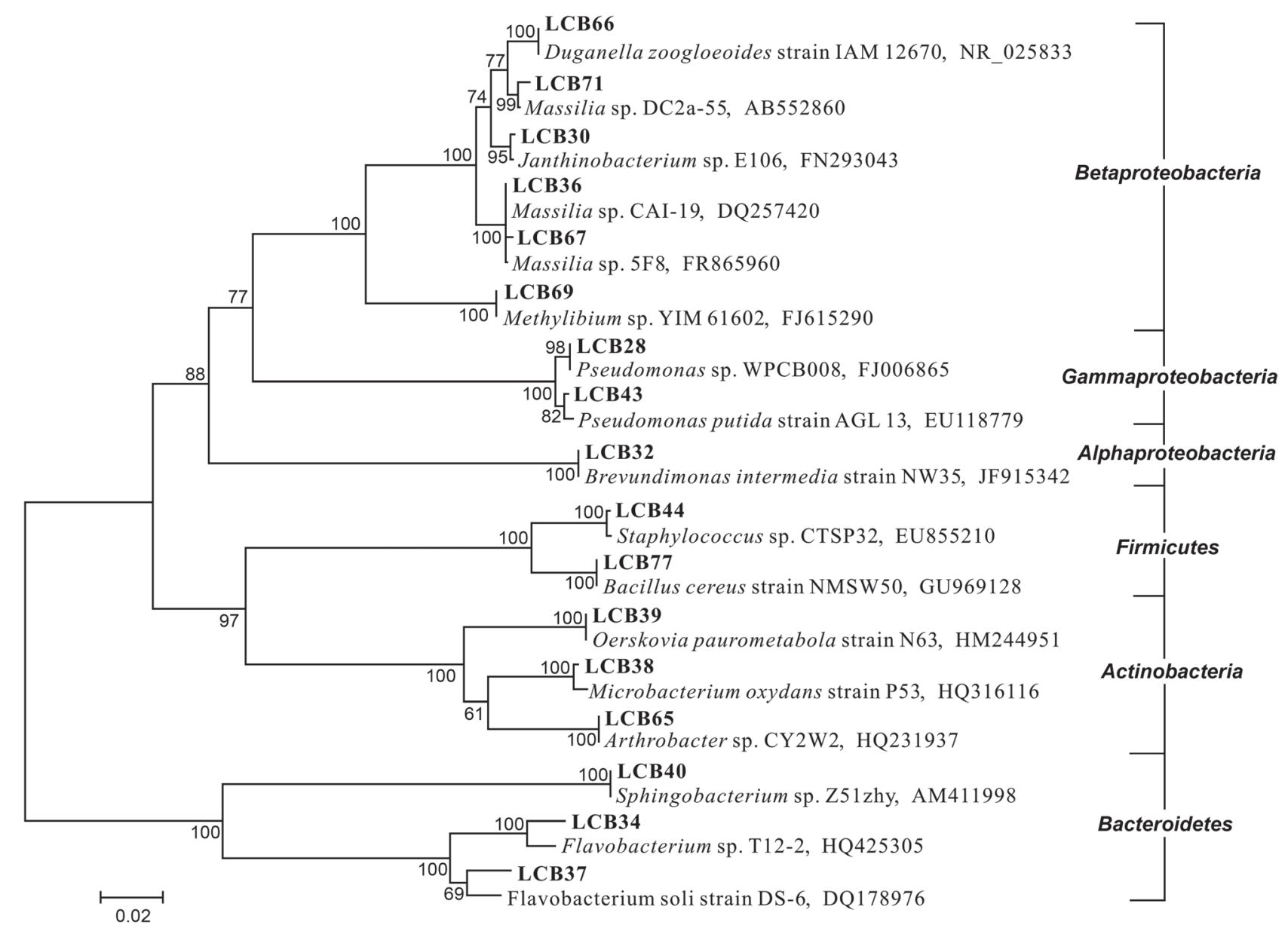

Fig. 2. Phylogenetic relationship based on $16 \mathrm{~S}$ rRNA gene sequences of culturable bacterial clones isolated from limestone rocks (in bold type) with closely related sequences from the GenBank database. Neighbor-joining trees; bootstrap values (1,000 replicates) are shown at the nodes

of GenBank database to obtain the most similar sequences. Table III shows the relationships between ITS sequences of fungi isolates from dolomite and limestone and the most similar sequences in GenBank database. The results indicated that 9 isolates from dolomite were classified into 1 phylum, 6 genera and 7 species; while the 8 strains of fungi isolates from limestone were divided into 1 phylum, 7 genera and 8 species. They all had high similarity (98 100\%) with the reported ITS sequences of GenBank database, including 12 strains with $100 \%$ similarity.

A phylogenetic tree was constructed based on the sequences with high similarity between the reference sequences in database and the strains isolated from dolomite and limestone, as shown in Fig. 3. The results manifested that 9 strains of fungal isolates from dolomite and 8 strains from limestone were Ascomycota. Among the fungal isolates from dolomite, 3 of them were Aspergillus, which was the genus with the most isolates. There were 2 strains with 100\% similarity to a strain of Aspergillus niger (EF592173), while the other one had $100 \%$ similarity with a strain of Aspergillus oryzae (HQ285588). There was also an isolate belonging to Penicillium, which was $100 \%$ similar with Penicillium crustosum (GQ340556). Besides, the other four strains were closely associated with Aureobasidium pullulans (JF439462) of Aureobasidium, Myrothecium verrucaria (GQ131886) of Myrothecium, Purpureocillium lilacinum (HM439952) of Paecilomyces and Trichoderma sp. (GQ497170) respectively, and the homology was as high as $99 \sim 100 \%$.

The 8 fungi isolates from limestone belonged to 7 genera of Ascomycota, including Alternaria, Bipolaris, Chaetomium, Cryptococcus, Fusarium, Penicillium and Trichoderma. Except that there were 2 isolates in Chaetomium, the other ones were divided into different genera. From the phylogenetic tree, it can be seen that isolate LCF94 and the fungal isolate from dolomite, namely DCF87 were 100\% similar, which suggested that they were the same kind of fungi. In addition, the similarity between them and P. crustosum (GQ340556) of Penicillium was $100 \%$. Moreover, isolate LCF98 and fungal isolate from dolomite DCF83 showed similarity of $100 \%$. It means that they were the same kind of bacteria and both of them were Trichoderma. Therefore, the fungal strains of Penicillium and Trichoderma were 
Table III

Similarity analysis of ITS sequences of isolates from dolomite and limestone rocks.

\begin{tabular}{|c|c|c|c|}
\hline $\begin{array}{l}\text { Representative isolate } \\
\text { (accession no.) }\end{array}$ & $\begin{array}{c}\text { No. of isolates } \\
\text { in OUT }\end{array}$ & Nearest type strain (accession no.) & $\begin{array}{c}\text { Similarity } \\
(\%)\end{array}$ \\
\hline \multicolumn{4}{|c|}{ Dolomite samples } \\
\hline Ascomycota & 9 & & \\
\hline Aureobasidium & 1 & & \\
\hline DCF84 (JN650590) & 1 & Aureobasidium pullulans (JF439462) & 100 \\
\hline Aspergillus & 3 & & \\
\hline DCF86 (JN650591) & 2 & Aspergillus niger (EF592173) & 100 \\
\hline DCF91 (JN650594) & 1 & Aspergillus oryzae (HQ285588) & 100 \\
\hline Myrothecium & 1 & & \\
\hline DCF88 (JN650593) & 1 & Myrothecium verrucaria (GQ131886) & 99 \\
\hline Penicillium & 1 & & \\
\hline DCF87 (JN650592) & 1 & Penicillium crustosum (GQ340556) & 100 \\
\hline Purpureocillium & 2 & & \\
\hline DCF81 (JN650588) & 2 & Purpureocillium lilacinum (HM439952) & 100 \\
\hline Trichoderma & 1 & & \\
\hline DCF83 (JN650589) & 1 & Trichoderma sp. (GQ497170) & 100 \\
\hline \multicolumn{4}{|c|}{ Limestone samples } \\
\hline Ascomycota & 8 & & \\
\hline Alternaria & 1 & & \\
\hline LCF97 (JN650600) & 1 & Alternaria sp. (HQ833813) & 100 \\
\hline Bipolaris & 1 & & \\
\hline LCF96 (JN650599) & 1 & Bipolaris sp. (FJ770073) & 98 \\
\hline Chaetomium & 2 & & \\
\hline LCF92 (JN650595) & 1 & Chaetomium sp. (HQ607819) & 99 \\
\hline LCF93 (JN650596) & 1 & Chaetomium nigricolor (JF439467) & 99 \\
\hline Cryptococcus & 1 & & \\
\hline LCF99 (JN650602) & 1 & Cryptococcus albidus (AF444355) & 100 \\
\hline Fusarium & 1 & & \\
\hline LCF95 (JN650598) & 1 & Fusarium oxysporum (EF495237) & 99 \\
\hline Penicillium & 1 & & \\
\hline LCF94 (JN650597) & 1 & Penicillium crustosum (GQ340556) & 100 \\
\hline Trichoderma & 1 & & \\
\hline LCF98 (JN650601) & 1 & Trichoderma sp. (GQ497170) & 100 \\
\hline
\end{tabular}

* The strains were clustered into operational taxonomic units (OTUs) at a level of sequence similarity $\geq 97 \%$

isolated from samples of dolomite and limestone. It can be seen that the two types of fungi existed in both kinds of rocks studied in the research.

\section{Discussion}

As a special habitat, carbonate rock provided a great challenge to the organisms living in it owing to the features of rocks, such as arid environment, nutrition deficiency, great temperature fluctuations, etc. However, there were various microorganisms on its surface and in its cracks, which played a crucial role in biogeochemical cycle. Although molecular biological method has been developed during exploring and revealing microbial diversity, it is still necessary to separate and purify microorganisms to understand their ecological functions in biosphere. Thereby, culture-dependent method is still an essential approach to research microbial diversity.

A total of 65 bacterial strains and 17 fungal strains were isolated from dolomite and limestone by using pure culture method. The 39 isolated bacterial strains from dolomite samples were divided into 4 phyla, 15 genera and 26 species; while the 26 bacterial strains of limestone were classified into 4 phyla, 13 genera 


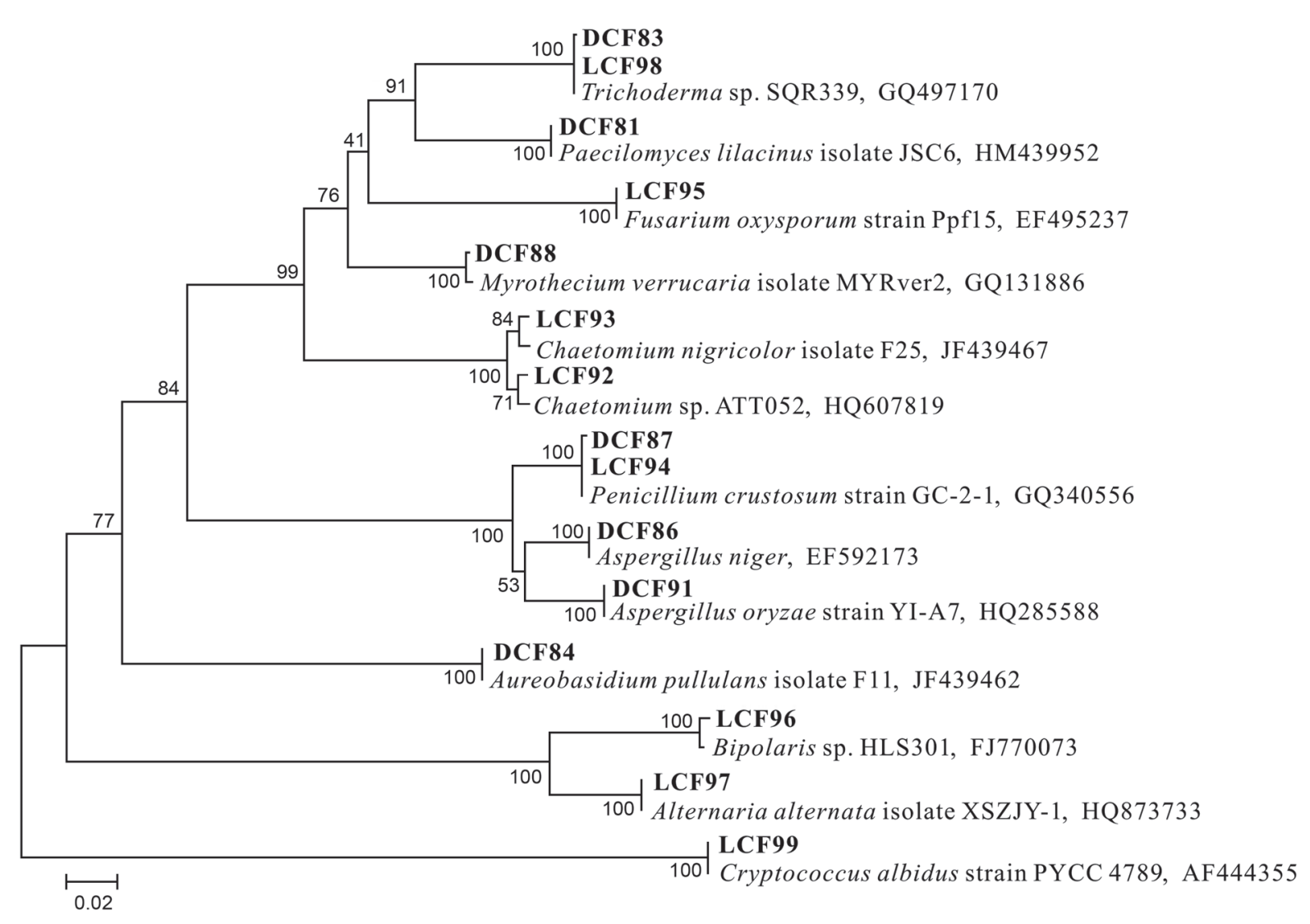

Fig. 3. Phylogenetic relationship based on ITS gene sequences of culturable fungal clones isolated from dolomite (DCF) and limestone (LCF) rocks (in bold type) with closely related sequences from the GenBank database. Neighbor-joining trees; bootstrap values (1,000 replicates) are shown at the nodes

and 17 species. The main phyla of the isolated bacteria from both kinds of rocks were consistent, but there were some differences in species. In addition, the diversity of bacteria was much higher than that of fungi. For these two kinds of rocks, Proteobacteria was the first dominant group, and Gammaproteobacteria occupied the greatest proportion. Besides, it was closely related to Pseudomonas in phylogeny to be the most dominant genera after isolation. Pseudomonas is a genus composed of ubiquitous metabolically versatile Gram-negative bacteria, capable to grow in a variety of environmental conditions (Belgini et al., 2014). Some researchers found that Pseudomonas also existed in the soil of Antarctic area even in deep sea and it was connected with polycyclic aromatic hydrocarbons (PAHs). Moreover, some Pseudomonas even was directly involved in degradation (Ma etal., 2006; Cui et al., 2008). A lot of pseudomonads bacteria were found in the dolomite and limestone rock endolithic environments, but their roles in rock environment were still unclear. The proportion of Actinobacteria in two kinds of rocks was greater. Meanwhile, the group is widespread in soil. An explanation for the high fraction of Actinobacteria in Guizhou karst region could be due to their strong cell wall, the capability of forming spores, and their high GC-content. These characteristics would allow their survival in harsh environments. Many bacteria belonging to Bacillus were isolated from the rock environment. Owing to the kind of bacteria forming the spores, which had powerful resistance to poor environment, they could survive in rock environment. Our results confirmed that members of the Proteobacteria, Actinobacteria and Bacillus are ecologically significant constituents of carbonate rocks. However, future work is needed to determine the functions of these important groups in karst environments.

There were only 9 and 8 strains of fungi isolated from dolomite and limestone respectively, which all belonged to Ascomycota. Besides, they were common fungi in environment which suggested that the culturable fungi resources were very limited on the two kinds of rocks. In view of numerous slow growing fungi colonize carbonate rocks, the cultivating time of fungi in the study might be short. With longer periods of time, it is possible that a more realistic and abundant fungal diversity would have been registered. Nevertheless, the roles of these fungi in rock environment have not been reported so far. Hence, it is necessary to study the functions of these microorganisms in karst rock environment, especially the roles in the process of weathering and pedogenesis of rocks by further utilizing these microbial resources. 
Combining the research results and our previous report about the endolithic microbial diversity in the carbonate rocks in karst area of Guizhou by using culture-independent method (Tang and Lian, 2012; Tang et al., 2012), it was indicated that the microbial diversity of carbonate rocks was abundant. There were autotrophic microorganisms, such as Cyanobacteria with nitrogen fixation and photosynthesis, anoxygenic phototrophic green non-sulfur bacteria, as well as heterotrophic microorganisms, for instance, Proteobacteria, Acidobacteria, Bacteroides, Firmicutes and heterotrophic fungi as well as Archaea. The autotrophic microorganisms could be the main primary producer in rock environment to provide nutrients for heterotrophic microorganism by fixing the carbon and nitrogen in the air. However, it was not enough for the numerous heterotrophic groups in rock environment merely depending on the nutrient substances supplied by autotrophic microorganisms (Lian et al., 2010). Owing to it tended to be more serious for heterotrophic microorganisms in rock environment, they survived by intercepting the few soil particles and nutrients in air and water except for being symbiotic with autotrophic microorganisms (Sterflinger, 2000; Viles and Gorbushina, 2003; Gorbushina, 2007; Lian et al., 2010; 2011). The rock microorganisms were in a relation of mutual cooperation and symbiosis (Lian et al., 2010). The main purpose of cooperation between different microorganism groups was to retain water and gain limited trace nutrients to sustain life activity and population continuity (Sterflinger, 2000; Gorbushina et al., 2003; Lian et al., 2011). Once the environmental conditions, such as temperature and humidity fitted for growth, they would quickly breed, spread and accelerate the weathering of minerals (Chen et al., 2014). The rock microorganisms in karst area played an irreplaceable role in the long geological evolution process of weathering and pedogenesis of carbonate rocks. Therefore, the future study is expected to further investigate the microbial community in the carbonate rock environments and deeply recognize it in special habitat so as to profoundly research its biogeochemistry function, such as the weathering and pedogenesis of carbonate rocks by using these microbial resources.

\section{Acknowledgements}

This research was jointly supported by the Natural Science Foundation of Guizhou Province of China (No. J [2014] 2168), the National Natural Science Foundation of China (No. 41503080; 41373078), the National Key Basic Research Program of China (No. 2013CB956700), the Key Agriculture R\&D Program of Guizhou Province (No. NY[2015]3001-1; NY[2013]3019), and the Provincial Science and Technology Major Project of the Ministry of Science and Technology of Guizhou Province (No. [2014] 6015-2-1).

\section{Literature}

Altschul S.F., W. Gish, W. Miller, E.W. Myers and D.J. Lipman. 1990. Basic local alignment search tool. J. Mol. Biol. 215: 403-410. Belgini D.R.B., R.S. Dias, V.M. Siqueira, L.A.B. Valadares, J.M. Albanese, R.S. Souza, A.P.R. Torres, M.P. Sousa, C.C. Silva, S.O. De Paula and others. 2014. Culturable bacterial diversity from a feed water of a reverse osmosis system, evaluation of biofilm formation and biocontrol using phages. World J. Microb. Biot. 30: 2689-2700.

Chen Y., B. Lian, Z.Y. Ying and Y. Tang. 2014. Weathering of carbonate rocks by biological soil crusts in Karst areas. J. Earth. Sci. 25: 662-667.

Cole J.R., B. Chai, T.L. Marsh, R.J. Farris, Q. Wang, S.A. Kulam, S. Chandra, D.M. McGarrell, T.M. Schmidt, G.M. Garrity and others. 2003. The ribosomal database project (rdp-ii): Previewing a new autoaligner that allows regular updates and the new prokaryotic taxonomy. Nucleic Acids Res. 31: 442-443.

Cui Z.S., Q.L. Lai, C.M. Dong and Z.Z. Shao. 2008. Biodiversity of polycyclic aromatic hydrocarbon-degrading bacteria from deep sea sediments of the Middle Atlantic Ridge. Environ. Microbiol. 8: 2138-2149.

De Leo F., A. Iero, G. Zammit and C.E. Urzì. 2012. Chemoorganotrophic bacteria isolated from biodeteriorated surfaces in cave and catacombs. Int. J. Speleol. 2: 125-136.

Dong H.L., J.A. Rech, H.C. Jiang, H. Sun and B.J. Buck. 2007. Endolithic cyanobacteria in soil gypsum: Occurrences in Atacama (Chile), Mojave (United States), and Al-Jafr Basin (Jordan) deserts. J. Geophys. Res. 112: 339-343.

Friedmann E.I. 1982. Endolithic microorganisms in the antarctic cold desert. Science 215: 1045-1053.

Gerrath J.F., J.A. Gerrath, U. Matthes and D.W. Larson. 2000. Endolithic algae and cyanobacteria from cliffs of the Niagara Escarpment, Ontario, Canada. Can. J. Bot. 78: 807-815.

Gorbushina A.A., K. Whitehead, T. Dornieden, A. Niesse, A. Schulte and J.I. Hedges. 2003. Black fungal colonies as units of survival: Hyphal mycosporines synthesized by rock-dwelling microcolonial fungi. Can. J. Bot-Revue Canadienne Botan. 81: 131-138.

Gorbushina A.A., J. Heyrman, T. Dornieden, M. GonzalezDelvalle, W. E. Krumbein, L. Laiz, K. Petersen, C. Saiz-Jimenez and J. Swings. 2004. Bacterial and fungal diversity and biodeterioration problems in mural painting environments of st. Martins Church (Greene-kreiensen, Germany). Int. Biodeterior. Biodegrad. 53: 13-24.

Gorbushina A.A. 2007. Life on the rocks. Environ. Microbiol. 9: 1613-1631.

Horath T. and R. Bachofen. 2009. Molecular characterization of an endolithic microbial community in Dolomite rock in the Central Alps (Switzerland). Microbial Ecol. 58: 290-306.

Huber T., G. Faulkner and P. Hugenholtz. 2004. Bellerophon: A program to detect chimeric sequences in multiple sequence alignments. Bioinformatics. 20: 2317-2319.

Kimura M. 1980. A simple model for estimating evolutionary rates of base substitutions through comparative studies of nucleotide sequences. J. Mol. Evol. 16: 111-120.

Krakova L., F. De Leo, L. Bruno, D. Pangallo and C. Urzi. 2015. Complex bacterial diversity in the white biofilms of the Catacombs of St. Callixtus in Rome evidenced by different investigation strategies. Environ. Microbiol. 84: 81-790.

Kumar S., K. Tamura and M. Nei. 2004. Mega3: Integrated software for molecular evolutionary genetics analysis and sequence alignment. Brief Bioinform. 5: 150-163.

Lian B., Y. Chen and Y. Tang. 2010. Microbes on carbonate rocks and pedogenesis in karst regions. J. Earth. Sci. 21: 293-296. 
Lian B., D.X. Yuan and Z.H. Liu. 2011. Effect of microbes on karstification in karst ecosystems. Chinese Sci. Bull. 56: 3743-3747.

Ma Y.F., L. Wang and Z.Z. Shao. 2006. Pseudomonas, the dominan polycyclic aromatic hydrocarbon-degrading bacteria isolated from Antarctic soils and the role of large plasmids in horizontal gene transfer. Environ. Microbiol. 8: 455-465.

Papida S., W. Murphy and E. May. 2000. Enhancement of physical weathering of building stones by microbial populations. Int. Biodeterior. Biodegrad. 46: 305-317.

Roldan M., C. Ascaso and J. Wierzchos. 2014. Fluorescent fingerprints of endolithic phototrophic cyanobacteria living within halite rocks in the Atacama desert. Appl. Environ. Microbiol. 80: 2998-3006. Selbmann L., E. Egidi, D. Isola, S. Onofri, G.S. de Hoog, S. Chinaglia, L. Testa, S. Tosi, A. Balestrazzi, A. Lantieri and others. 2013. Biodiversity, evolution and adaptation of fungi in extreme environments. Plant Biosyst. 147: 237-246.

Sigler W.V., R. Bachofen and J. Zeyer. 2003. Molecular characterization of endolithic cyanobacteria inhabiting exposed dolomite in central Switzerland. Environ. Microbiol. 5: 618-627.

Spring S., N. Brinkmann, M. Murrja, C. Sproer, J. Reitner and H.P. Klenk. 2015. High diversity of culturable prokaryotes in a lithifying hypersaline microbial mat. Geomicrobiol. J. 32: 332-346. Stackebrandt E. and J. Ebers. 2006. Taxonomic parameters revisited: Tarnished gold standards. Microbiol. Today 33: 1525-1155. Sterflinger K. 2000. Fungi as geologic agents. Geomicrobiol. J. 17: 97-124.

Tamaki H., Y. Sekiguchi, S. Hanada, K. Nakamura, N. Nomura M. Matsumura and Y. Kamagata. 2005. Comparative analysis of bacterial diversity in freshwater sediment of a shallow eutrophic lake by molecular and improved cultivation-based techniques. Appl. Environ. Microbiol. 71: 2162-2169.

Tang Y. and B. Lian. 2012. Diversity of endolithic fungal communities in dolomite and limestone rocks from Nanjiang Canyon in Guizhou karst area, China. Can. J. Microbiol. 58: 685-693.

Tang Y., B. Lian, H.L. Dong, D.F. Liu and W.G. Hou. 2012. Endolithic bacterial communities in dolomite and limestone rocks from the Nanjiang Canyon in Guizhou karst area (China). Geomicrobiol. J. 29: 213-225.

Thompson J.D., T.J. Gibson, F. Plewniak, F. Jeanmougin and D.G. Higgins. 1997. The clustal_x windows interface: Flexible strategies for multiple sequence alignment aided by quality analysis tools. Nucleic Acids Res. 25: 4876-4882.

Viles H.A. and A.A. Gorbushina. 2003. Soiling and microbial coloniastion on urbon roadside limestone: A three year study in Oxford England. Build Environ. 38: 9-10.

Walker J.J. and N.R. Pace. 2007a. Endolithic microbial ecosystems. Annu. Rev. Microbiol. 61:331-347.

Walker J.J. and N.R. Pace. 2007b. Phylogenetic composition of rocky mountain endolithic microbial ecosystems. Appl. Environ. Microbiol. 73: 3497-3504.

Wierzchos J., C. Ascaso and C.P. McKay. 2006. Endolithic cyanobacteria in halite rocks from the hyperarid core of the Atacama desert. Astrobiology 6: 415-422.

Wong F.K.Y., M.C.Y. Lau, D.C. Lacap, J.C. Aitchison, D.A. Cowan and S.B. Pointing. 2010. Endolithic microbial colonization of limestone in a high-altitude arid environment. Microbial. Ecol. 59: 689-699. 
